were insane, and when the latter visited him said he was an impostor. He also said that the person who visited him there (the nephew) was not the same individual who had visited him at his home; that he could with difficulty recognise that his doctor who visited him there was the man he really knew; and that the house of a neighbour was an asylum. He acknowledged that he had made a fresh will, and said that it had now received the sanction of the Lord Chancellor, "or whoever was the proper authority." He died in the institution on October 18th, having become demented.

A "caveat" was entered against the will made in July, 1899 , and another was also entered by the executors of the will of 1899 . The money having been left to charities and not to individuals, it became the function of the Attorney-General, as representing the public, to consider the facts on behalf of the charitable bodies to whom the property was left. On consideration of the proofs which could be produced of the patient's insanity during the previous three years, the evidence of insanity shown in the medical certificates and in my report of his condition on my visit to him at the Holloway Sanatorium, on July 26th, 1899, the Attorney-General concluded that the evidence of insanity at the time when the will of July 3 rd, 1899 , was made was so strong that there would be no likelihood of its being successfully upheld, and therefore he decided not to oppose probate of the will made in 1892 .

The case was brought before the Probate Division on February 12th, 1900 . Evidence was given by the clerk to the firm of solicitors who prepared the will of 1892 as to due execution of such will; by the nephew as to the deceased's insanity in March, 1899, and in July before his admission to the Holloway Sanatorium: and by me as to his insanity at my visit. No evidence was brought forward in favour of his being of sound disposing mind in July, 1899, and the judge found that he was insane at the time of execution of the second will, that of 1892 being allowed to stand.

In this case the evidence of such insanity as to vitiate the will of 1899 was so strong that there was no case on the other side. The patient's mind was so possessed by the delusion that his relatives were insane that he was unable to take their claims into consideration. It will be noted that there was evidence of "eccentricity," not improbably amounting to insanity, existing at the time of execution of the first will; but apparently the testamentary capacity had not been affected by it.

\title{
Aphasia and Will-making.
}

An interesting case, lately heard in the Probate Court before the President, Sir Francis Jeune, is noticed as an occasional article on p. 320.-ED.

\section{ASYLUM NEWS.}

\section{The Cost of Asylums.}

The London County Council lately considered a report by the General Purposes Committee upon the increased cost over the estimates of the Bexley and Horton Asylums. It appears from the discussion that the "estimates" were rather of the nature of a sum which, at the time, it was hoped might prove sufficient, and was rather intended as a check upon extravagance than as a figure arrived at by measuring up of quantities and the careful analysis of specifications. The Committee of Inquiry assert that there has been good value for money, and that the urgent demand for accommodation, and the excessive cost of boarding cases out of London, justified the pressing forward of the erections with as little delay as possible. Comparing the cost per head at the Bexley Asylum with that at other recently constructed asylums, it is clear that the actual cost has not been excessive. At Claybury the cost per bed was 6236 , at the new West Somerset Asylum $£ 377$, while the projected North Stafford Asylum is estimated to cost for the building alone $£ 280$ per bed. It is stated that the Asylums Committee is considering the propriety of varying the stereotyped plan of erecting huge palatial buildings for the insane in favour of detached residences. 